Kidney transplant outcomes after medically assisted death

\title{
Kidney transplant outcomes after medical assistance in dying
}

Patrick P. Luke, $\mathrm{MD}^{1}$; Anton Skaro, $\mathrm{MD}, \mathrm{PhD}^{1}$; Alp Sener, $\mathrm{MD}, \mathrm{PhD}^{1}$; Ephraim Tang, MD ${ }^{1}$; Max Levine, MD ${ }^{1}$; Samir Sami, MD ${ }^{1}$; John Basmaji, MD²; Ian Ball, MD ${ }^{2}$ ${ }^{1}$ Department of Surgery, Western University, London, ON, Canada; ${ }^{2}$ Department of Medicine, Western University, London, ON, Canada

Cite as: Luke PP, Skaro A, Sener A, et al. Kidney transplant outcomes after medical assistance in dying. Can Urol Assoc J 2021 September 24; Epub ahead of print. http://dx.doi.org/10.5489/cuaj.7304

Published online September 24, 2021

Corresponding author: Dr. Patrick P. Luke, Department of Surgery, Division of Urology, Western University, London, ON, Canada; patrick.luke@lhsc.on.ca

$* * *$

\section{Abstract}

Introduction: After nearly four years of Canadian experience with medical assistance in dying (MAiD), the clinical volume of organ transplantation following MAiD remains low. This is the first Canadian report evaluating recipient outcomes from kidney transplantation following MAiD.

Methods: This was a retrospective review of the first nine cases of kidney transplants following MAiD at a Canadian transplant center.

Results: Nine patients underwent MAiD followed by kidney retrieval during the study period. Their diagnoses were largely neuromuscular diseases. The mean warm ischemic time was 20 minutes (standard deviation [SD] 7). The nine recipients had a mean age of 60 (SD 19.7). The mean cold ischemic time was 525 minutes (SD 126). Delayed graft function occurred in only one patient out of nine. The mean 30-day creatinine was 124 umol/L (SD 52). The mean three-month creatinine was 115 umol/L (SD 29).

Conclusions: We report nine cases of kidney transplantation following MAiD. The process minimized warm ischemia, resulting in low delayed graft function rates, and acceptable post-transplant outcomes. Further large-scale research is necessary to optimize processes and outcomes in this novel clinical pathway. 
Kidney transplant outcomes after medically assisted death

\section{Introduction}

Following the Supreme Court of Canada's Carter Decision, medical assistance in dying (MAID) became possible with individual court orders in February, 2016, and later without court involvement when legislation was passed on June 17, 2016 ${ }^{1}$. After nearly four years of Canadian experience with MAID, the clinical volume of organ transplantation following MAID remains relatively low ${ }^{1}$. This is the first Canadian report evaluating recipient outcomes from kidney transplantation following MAID.

It cannot be overemphasized that the primary motivation for transplantation following MAID is to support the wishes of patients undergoing MAID. To qualify for MAID in Canada, two independent assessors (medical doctors or nurse practitioners) must deem patients to have a grievous and irremediable medical condition. Patients must demonstrate a voluntary request that is not the result of outside pressure or influence, and must be able to provide informed consent immediately prior to the procedure ${ }^{2}$. Further, to ensure a completely altruistic decision to donate their organs following MAID, patients are not approached about organ donation until their eligibility for MAID has been established.

There are currently three distinct methods for deceased organ donation in Canada: donation after neurologic death determination (NDD), donation after circulatory death determination (DCDD), and more recently, donation after MAID. When donation after MAID was first implemented, the process was based largely on the existing DCDD process, although it has been suggested that MAID may merit its own clinical pathway ${ }^{3}$.

\section{Methods}

A retrospective review of all kidney transplants following MAID at London Health Sciences Centre between January 2018 and January 2020 was conducted. The study was approved by the Western University Research Ethics Board (REB\# 7089). The protocol surrounding transplant following MAID was established by our hospital MAID Committee 4 and transplant surgeons; the final document was then approved by the hospital medical advisory committee. Decision to perform MAID was established weeks prior to the donation event. In many cases, the patient approached the health care providers with regards to opportunity to donate. The hospital had time to organize withdrawal, donation and transplant teams well ahead of the withdrawal event. Lifeending therapy varies according to provider, but generally includes a combination of benzodiazepene (midazolam), arrhythmic (lidocaine with epinephrine IV, potassium chloride), general anesthetic (propofol), muscle relaxant (rocuronium). Drug administration is not standardized, however treatment intention is to end life without suffering. At our centre, MAID procedures took place in a private room directly across the hall from the operating room. This provided privacy for the patients and their families, while affording a very short transport time to the operating room. As per our 
provincial protocol, in cases where two kidneys were recovered, one was kept at our centre for transplant and one was shared provincially to the recipient with the highest points on the waitlist. We only reported on recipient outcomes in kidneys transplanted at our centre.

Recipient immunotherapy included induction therapy with IL-2 blockade, or polyclonal anti-thymocyte globulin, as well as maintenance with tacrolimus, mycophenolate mofetil and corticosteroids. Tacrolimus levels were maintained at trough levels of $5-8 \mathrm{ng} / \mathrm{ml}$ for the first 3 months.

\section{Results}

Nine patients underwent MAID followed by kidney retrieval during the study period. Their diagnoses were largely neuromuscular diseases (Amyotrophic Lateral Sclerosis and Multiple Sclerosis), as well as one patient with severe disability post-trauma and one patient with heart failure. Donor demographics are displayed in Table 1. The mean warm ischemic time (defined as the time between MAID initiation and cold perfusion) was 20 minutes (SD 7). Our institution has recently implemented the use of potassium chloride for organ donation following MAID, which will likely further reduce the warm ischemic time ${ }^{5}$.

The nine recipients had a mean age of 60 (SD 19.7). The causes of kidney failure included diabetic nephropathy, IgA nephropathy, focal segmental glomerulosclerosis, lupus nephritis, polycystic kidney disease and hypertensive nephrosclerosis (Table 2). The mean cold ischemic time was 525 minutes (SD 126). Recipients' mean length of hospital stay was 12 days (SD 5.4). Delayed graft function occurred in only 1 patient out of nine and was later identified as Banff 2 a cell mediated rejection and possible antibody mediated rejection. The patient was treated with thymoglobulin, plasma exchange, intravenous immunoglobulin and required 3 days of hemodialysis. The mean 30 day creatinine was $124 \mathrm{umol} / \mathrm{L}$ (SD 52). The mean 3 month creatinine was $115 \mathrm{umol} / \mathrm{L}$ (SD 29).

There were four 90-day post-operative complications and one death in this series: one wound dehiscence, one acute coronary syndrome that was managed medically, one perinephric fluid collection that required drainage and one patient with gastrointestinal complications from their immunosuppressive agents. There was one peri-operative death related with reaction to anti-thymocyte globulin. This patient had immediate graft function following the transplant. 
Kidney transplant outcomes after medically assisted death

\section{Discussion}

In these first 9 cases of kidney transplantation following MAID, only 1 case of delayed graft function had occurred. While we reiterate that the primary driver of transplantation following MAID is to respect donors' autonomy, it is important to acknowledge that preliminary evidence and common sense suggest that this organ donation pathway provides high quality kidneys for recipients. In DCDD, many potential donors do not progress to circulatory arrest within a time interval that is consistent with the retrieval of suitable organs for transplant. This leads to retrieval teams having to wait up to two or more hours in an operating room (OR) where donors fail to progress, yielding no organs for transplant. These procedures are resource intensive incurring travel costs, lost OR time, and potential donor family and recipient disappointment. In cases in which DCDD donors do progress to death within the acceptable timeframe, warm ischemic time of up to 120 minutes may occur, leading to significant rates of delayed graft function and the potential for primary non-function.

Kidney retrieval following MAID allows patients the opportunity to donate organs that have sustained a predictably short warm ischemic time. This is likely associated with the low rate of delayed graft function in our patient cohort. Although other countries that have performed organ donation after euthanasia, there has been a paucity of functional reports following renal transplantation. ${ }^{6,7}$ Therefore, we believe our Canadian report of kidney graft outcomes following MAID promotes the concept of organ donation following euthanasia, but our data are limited by the small number of patients and short term follow-up. Ongoing work in this area should focus on improving patient awareness of this potential opportunity, creating a distinct clinical pathway for organ retrieval following $\mathrm{MAID}^{3}$, and performing larger scale research describing clinical outcomes and optimizing the protocols.

\section{Conclusions}

We report 9 cases of kidney transplantation following medical assistance in dying. This process minimized warm and cold ischemia, with resultant low delayed graft function rates, and acceptable short-term results. Further large-scale research is necessary to optimize processes and outcomes in this novel clinical pathway. 
Kidney transplant outcomes after medically assisted death

\section{References}

1. Ball IM, Healey A, Keenan S, et al. Organ Donation after Medical Assistance in Dying — Canada's First Cases. N Engl J Med. 2020;382(6):576-577. doi:10.1056/NEJMc1915485

2. www.canada.ca/en/health-canada/services/medical-assistance-dying.html, accessed May 7, 2020

3. Ball IM, Sibbald R, Truog RD. Voluntary euthanasia - implications for organ donation. $N$ Engl J Med 2018; 379:909-911. doi: 10.1056/NEJMp1804276

4. Ball IM, Hodge B, Jansen S, Nickle S, Sibbald RW. A Canadian hospital's initial MAID experience: A health-care systems review. J Pall Care 2018; 34(2): 78-84.

5. Ball IM, Martin C, Sibbald R. Potassium chloride for organ donation following medical assistance in dying. Can J Anesth 2020. doi.org/10.1007/s12630-02001603-w

6. Wijingaarden AKS, Van Westerloo DJ, Ringers J. Organ donation after euthanasia in the Netherlands: a case report. Transplant Proc 2016; 48(9): 30613063.

7. Ysebaert D, Van Beeumen G, De Greef K et al. Organ procurement after euthanasia: Belgian experience. Transplant Proc 2009; 41(2): 585-586.

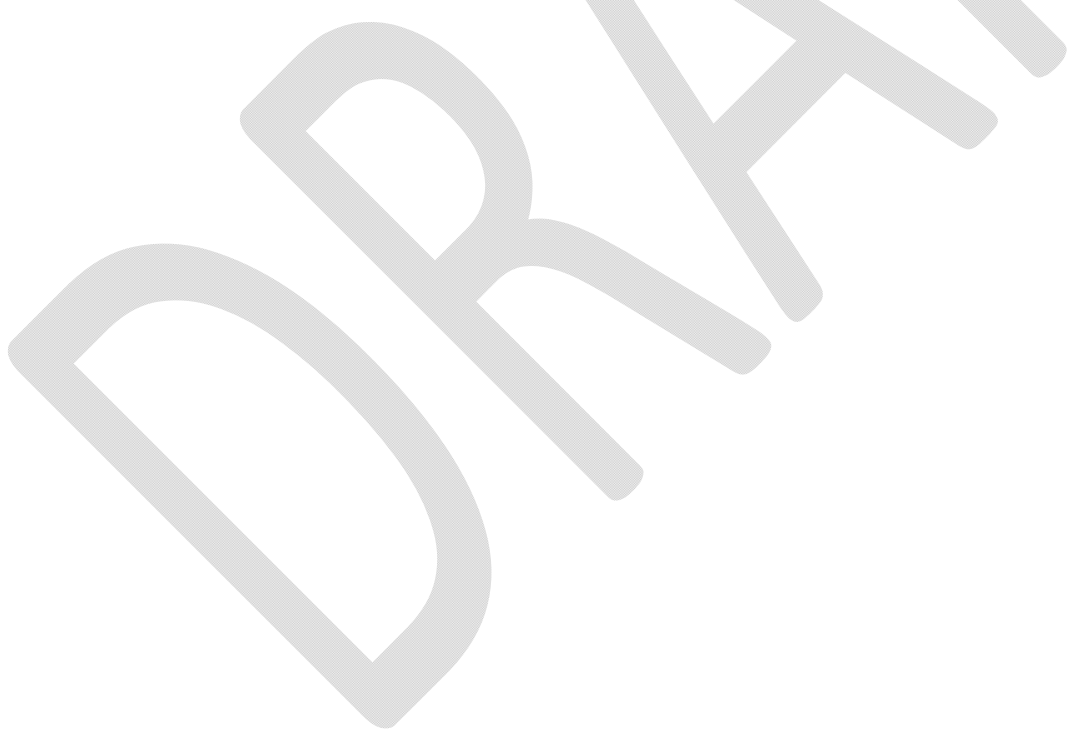


Kidney transplant outcomes after medically assisted death

Figures and Tables

\begin{tabular}{|l|c|c|c|c|c|}
\hline \multicolumn{7}{|l|}{ Table 1. Donor characteristics-related with MAiD kidney donation } \\
\hline Donor & Age & Sex & Reasons for seeking MAiD & Donated organ(s) & $\begin{array}{c}\text { WIT } \\
\text { (minutes) }\end{array}$ \\
\hline 1 & 25 & $\mathrm{M}$ & Cerebral palsy & Liver/kidney & 31 \\
\hline 2 & 67 & $\mathrm{M}$ & Fall & Kidney & 30 \\
\hline 3 & 40 & $\mathrm{M}$ & Amyotrophic lateral sclerosis & Kidney/pancreas & 16 \\
\hline 4 & 35 & $\mathrm{M}$ & Heart failure & Kidney & 17 \\
\hline 5 & 55 & $\mathrm{M}$ & Amyotrophic lateral sclerosis & Kidney & 16 \\
\hline 6 & 60 & $\mathrm{~F}$ & Multiple sclerosis & Kidney & 10 \\
\hline 7 & 46 & $\mathrm{~F}$ & Amyotrophic lateral sclerosis & Kidney & 23 \\
\hline 8 & 46 & $\mathrm{~F}$ & Huntington's disease & Kidney & 16 \\
\hline 9 & 64 & $\mathrm{M}$ & Amyotrophic lateral sclerosis & Kidney & 19 \\
\hline $\begin{array}{l}\text { Total, } \\
\text { mean }\end{array}$ & 48.67 & & & & $20(7)$ \\
(SD) & $(14)$ & & & & \\
\hline
\end{tabular}

F: female; M: male; MAiD; medical assistance in dying; SD: standard deviation; WIT: warm ischemic time. 
Kidney transplant outcomes after medically assisted death

\begin{tabular}{|c|c|c|c|c|c|c|c|c|c|}
\hline Recipient & Age & Sex & Kidney disease & $\begin{array}{c}\text { Cold } \\
\text { ischemia } \\
\text { time } \\
\text { (minutes) }\end{array}$ & $\begin{array}{l}\text { LOS } \\
\text { (day) }\end{array}$ & DGF & $\begin{array}{l}\text { Postoperative } \\
\text { dialysis (day) }\end{array}$ & $\begin{array}{c}\text { 30-day Cr } \\
\text { (umol/L) }\end{array}$ & $\begin{array}{c}\text { 3-month } \\
\mathrm{Cr} \\
\text { (umol/L) }\end{array}$ \\
\hline 1 & 18 & M & $\begin{array}{l}\text { Type 1A glycogen } \\
\text { storage disease }\end{array}$ & 355 & 16 & No & & 70 & 73 \\
\hline 2 & 78 & M & $\begin{array}{c}\text { Diabetic } \\
\text { nephropathy }\end{array}$ & 623 & 13 & No & - & 124 & 113 \\
\hline 3 & 38 & M & Type 1 diabetes & 563 & 8 & No & - & 52 & 112 \\
\hline 4 & 71 & $\mathrm{~F}$ & $\begin{array}{l}\text { Lupus nephritis and } \\
\text { diabetic nephropathy }\end{array}$ & 421 & - & Deceased & - & - & - \\
\hline 5 & 61 & M & $\begin{array}{c}\text { Diabetic } \\
\text { nephropathy }\end{array}$ & 630 & 13 & No & - & 145 & 120 \\
\hline 6 & 72 & $\mathrm{~F}$ & ADPKD & 468 & 6 & No & - & 95 & 94 \\
\hline
\end{tabular}


Kidney transplant outcomes after medically assisted death

\begin{tabular}{|l|c|c|c|c|c|c|c|c|c|}
\hline 7 & 67 & $\mathrm{M}$ & $\begin{array}{c}\text { DM IgA } \\
\text { nephropathy }\end{array}$ & 717 & 5 & No & - & 126 & 104 \\
\hline 8 & 66 & $\mathrm{M}$ & $\begin{array}{c}\text { Diabetic } \\
\text { nephropathy }\end{array}$ & 575 & 13 & No & - & 211 & 169 \\
\hline 9 & 73 & $\mathrm{M}$ & $\begin{array}{c}\text { Hypertensive } \\
\text { nephrosclerosis }\end{array}$ & 373 & 21 & Yes & 3 & 169 & 138 \\
\hline Mean (SD) & $\begin{array}{c}60 \\
(19.7)\end{array}$ & - & - & $525(126)$ & $\begin{array}{c}12 \\
(5.4)\end{array}$ & - & $124(52)$ & $115(29)$ \\
\hline
\end{tabular}

ADPKD: autosomal dominant polycystic kidney disease; Cr: creatinine; DGF: delayed graft function; DM: diabetes mellitus; F: female; LOS: length of stay; M: male; SD: standard deviation. 